\title{
A pain in the neck
}

\author{
Tania Minns, Ray Raj, Kate Clark \\ Emergency Department, Royal Liverpool University Hospital, Liverpool, UK
}

Correspondence to Dr Ray Raj, ray.raj@rlbuht.nhs.uk

\section{Summary}

A 21 -year-old man presented to the emergency department with pain and swelling to the right side of his neck and chest wall with associated shortness of breath. Two days earlier, while playing football, he had been involved in a minor collision with another player where he was struck on the right side of his head, but had managed to continue playing. On examination, the patient had extensive cervical surgical emphysema. There were no further positive findings on respiratory and general examination. A chest x-ray demonstrated no rib or clavicular fractures and no pneumothorax. Therefore, a CT was undertaken to ascertain the cause of the surgical emphysema. This demonstrated a pneumomediastinum, pneumopericardium and extradural air in the spinal column in addition to the subcutaneous air. The CT identified no bony trauma and no other injuries. The symptoms resolved spontaneously and follow-up radiography, 9 days later, showed no residual air.

\section{BACKGROUND}

This case is unusual due to the presence of large amounts of air in the tissues following a minor collision with no identifiable injuries. Pneumomediastinum and surgical emphysema have been repeatedly demonstrated following blunt chest trauma, especially high impact trauma involving significant forces of deceleration; often associated with large pneumothoraces. It has also been described in some cases following isolated facial trauma with resultant facial fractures. However, it is extremely unusual in this setting, where the trauma was of low velocity and associated with no fractures, particularly when associated with pneumopericardium and extradural air.

\section{CASE PRESENTATION}

A 21-year-old man presented to emergency department after his general practitioner identified surgical emphysema following a minor sports accident. On presentation, the patient complained of anterior neck and chest pain which had worsened since the injury 2 days previously. The patient had been involved in a collision with another player while playing football; the other player's shoulder made contact with his right temporal area. The patient experienced immediate pain over the right mastoid, transient blurring of vision and 'muffled' hearing. The patient was knocked to the floor but was able to get up and continue to the end of the game.

The patient initially noticed swelling in the area of the right mastoid which progressed over the next day to include the upper anterior chest wall. The swollen area was tender to palpation, and as it progressed, was increasingly associated with pleuritic chest pain and shortness of breath. The patient also complained of persisting reduction in hearing bilaterally. The patient denied a headache or any other neurological symptoms.

The patient had no medical or surgical history, no known drug allergies and was only taking short-term analgesia (codydramol and ibuprofen) with no regular medications. The patient was a full time student and an ex-smoker of 4 months (less than half a pack year).
On examination, the patient was apyrexial, had a pulse rate of $60 \mathrm{bpm}$ and was mildly hypertensive $(150 / 74 \mathrm{~mm}$ $\mathrm{Hg}$ ). He had a respiratory rate of 15 breaths per min, with saturations of $95 \%$ on room air. There was no accessory muscle use, good equal chest expansion and air entry was noted with no added sounds. Abdominal examination was unremarkable.

Neurological examination was also normal apart from a slight visual field defect which was longstanding from a previous problem. There was also a reduction in hearing on the right side but tympanic membranes could not be visualised due to wax in the auditory meatus.

Swelling was evident in the anterior triangles of the neck and over the superior anterior chest wall. It was tender to palpate over this area, particularly over the right clavicle, with obvious crepitus.

\section{INVESTIGATIONS}

Due to the presence of surgical emphysema, the suboptimal saturations, the history of trauma and the progressive pleuritic chest pain and shortness of breath, a chest x-ray was ordered to exclude fractures and a pneumothorax. No fractures or pneumothoraces were evident on the x-ray but extensive surgical emphysema and a pneumomediastinum was noted (figure 1).

CT scanning of the head (including facial bones), neck and chest was conducted to further characterise the extent of the air and its potential source. The CT identified no fractures of the skull, facial bones, ribs or clavicles (figure 2). It also demonstrated no tracheobronchial or upper gastrointestinal injury. There was no apparent source for the demonstrated pneumomediastinum, pneumopericardium, extradural air and extensive surgical emphysema. (However, the radiologist did comment on a small focus of air in the pleural space, which confirms the theory that the air found in the soft tissues of this patient was most probably due to rupture of a small subpleural alveolus which had self-sealed). No further investigations were done. 


\section{BMJ Case Reports}

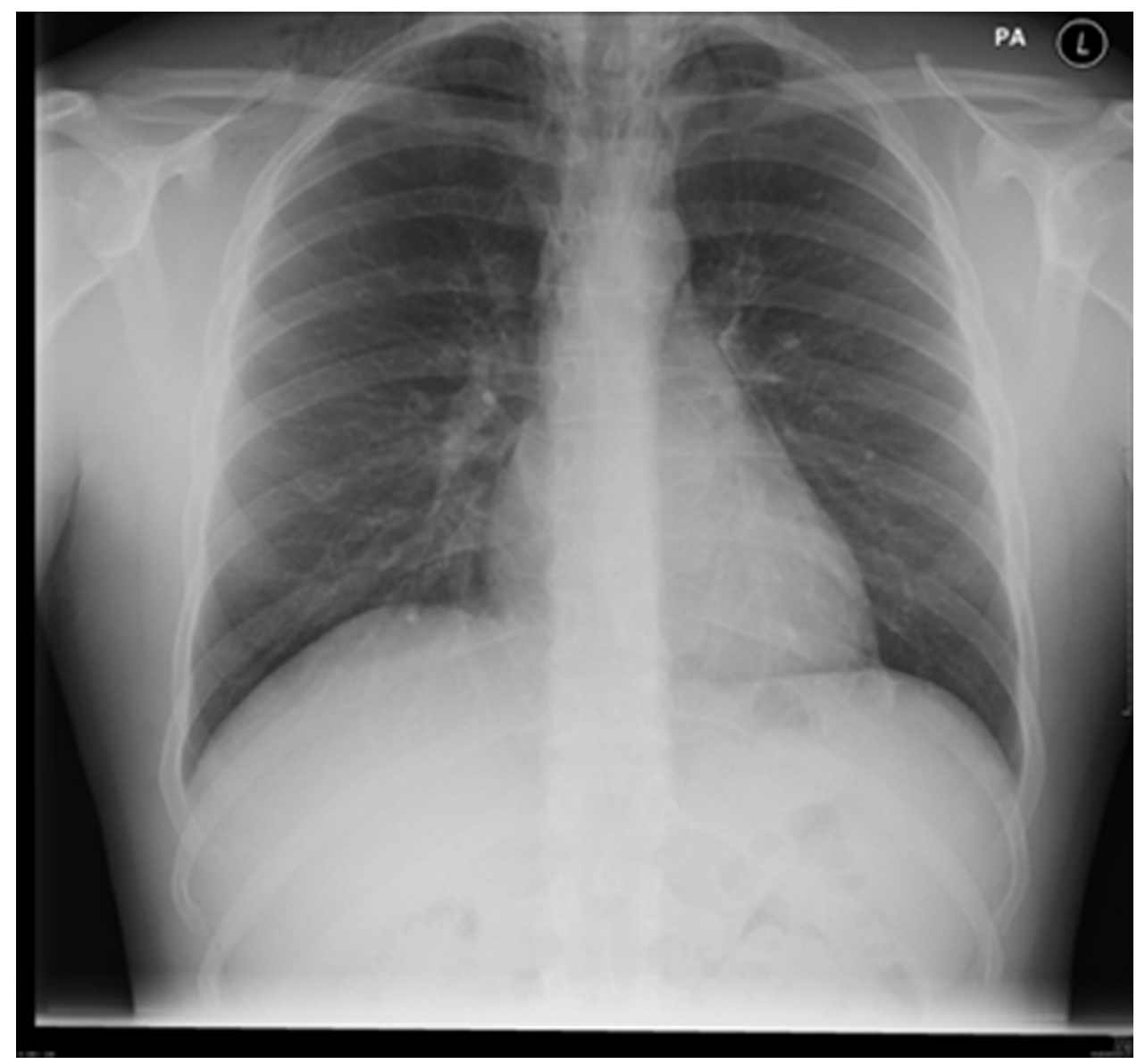

Figure 1 Chest x-ray (CXR): initial CXR showing obvious surgical emphysema and subtle pneumomediastinum/pneumopericardium.

\section{TREATMENT}

This patient was managed conservatively and was admitted to the clinical decision unit for a short period of observation. As he remained well, he was discharged with a follow-up appointment in the emergency department review clinic with advice to return immediately should his condition deteriorate.

\section{OUTCOME AND FOLLOW-UP}

At the follow-up appointment, 9 days later, all symptoms and signs had resolved and a repeat chest x-ray was normal. He was therefore discharged from clinic with advice regarding flying and diving.

Telephone follow-up was conducted at 4 weeks and there was no recurrence of symptoms and no further action was deemed necessary.

\section{DISCUSSION}

Aliterature searchwas performed via medline(1950-present) using the terms pneumomediastinum (expl), pneumopericardium, extradural air or pneumorrhachis and surgical emphysema (expl). No cases were found that illustrate the combination of surgical emphysema, pneumomediastinum, pneumopericardium and penumorrhachis in an adult patient. Most cases identified with significant air leaks in adults, involved intervention and instrumentation (intubation, colonoscopy, dental extraction, laparoscopy etc), major trauma, bronchial hyperreactivity (asthma, cocaine etc) or a valsalva-like manoeuvre (for instance in sustained forceful vomiting, coughing and childbirth).

A spontaneous pneumomediastinum can occur in the absence of injury due to the Macklin effect. This is thought to be due to alveolar rupture and tracking of air into the interstitial plane, along the bronchovascular sheaths, into the mediastinum. Predisposing features include precipitating events which transiently increases trans-alveolar pressure or pathology that weakens the alveolar wall, such as asthma or infection. Spontaneous pneumomediastinum has also been described extending into the deep fascial planes of the neck producing surgical emphysema as well as tracking of air into the extradural spaces and, via the diaphragmatic hiatus, into the peritoneum or retroperitoneum. It has been suggested by Al-Mufarrej et al that a pneumomediastinum cannot be attributed solely to the Macklin effect without active exclusion of an aerodigestive tract injury and pulmonary parenchymal disease (bronchoscopy and contract swallow study). As there was no suggestion of an injury to these structures either clinically, on radiography or $\mathrm{CT}$, no further investigation was considered necessary to exclude these injuries in this patient.

Dyste et a $\mathcal{R}$ describes a case of a 17-year-old American football player who sustained a light blow to the sternum during training and developed chest tightness, shortness of breath, dysphagia and vocal changes after finishing the practice. The patient was diagnosed with a pneumomediastinum and the author notes that this diagnosis should be considered in athletes with retrosternal chest pain and 


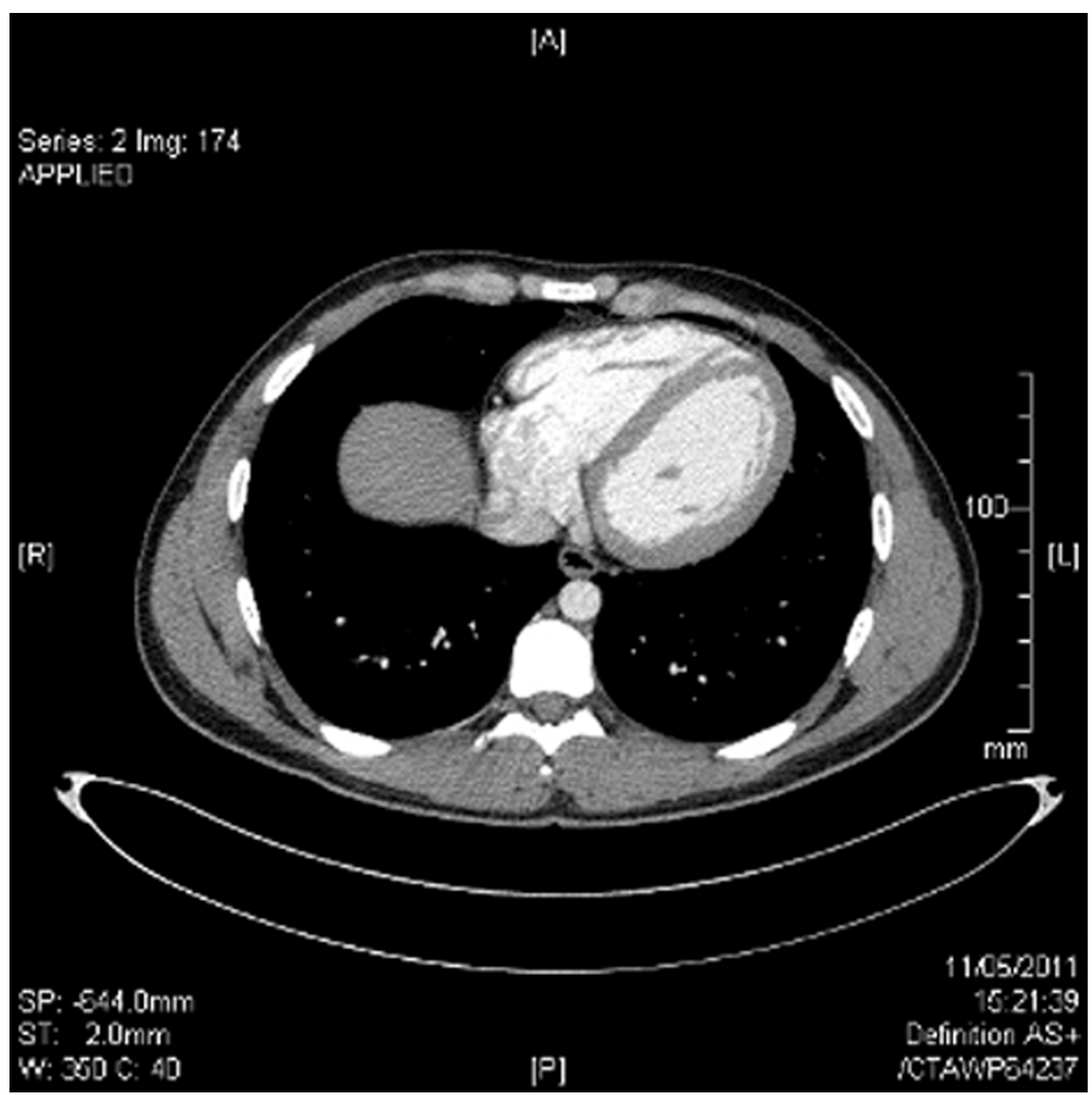

Figure 2 CT: a single slice from the CT showing obvious pneumopericardium.

that a slight amount of force is sufficient to sustain such an injury. Goh et a ${ }^{\beta}$ described the case of a 22 -year-old basketball player who, following a collision with another player, developed gradual onset chest and neck pain and was found to have surgical emphysema, pneumomediastinum and extradural air. This is a very similar precipitating event and clinical presentation to our patient, however, no air in the pleural space and no pneumopericardium was demonstrated in this case. In both of the above cases, symptoms resolved spontaneously and follow-up imaging showed complete resolution.

Extradural air, while difficult to distinguish from intradural air on CT, is often benign and self-limiting and rarely associated with neurological manifestations. For this reason, given the lack of neurological signs on examination, no further neurological investigation was considered necessary in this patient. This approach was also taken by Al-Mufarrej et al. ${ }^{1}$

Pneumopericardium is very rarely reported and hence its incidence is unknown. There is a potential for the development of a tension pneumopericardium, a life-threatening complication which can lead to haemodynamic collapse and cardiac arrest. Two case series have been conducted of blunt trauma patients with pneumopericardium, ${ }^{45}$ in both series $37 \%$ of patients developed a tension pneumopericardium. This has a mortality of up to $50 \% .{ }^{6}$ As no previous reports show the association between surgical emphysema, pneumomediastinum, pneumorrhachis and pneumopericardium after minor trauma with no identifiable injury, a tension pneumopericardium should be actively excluded in such presentations. Haemodynamic instability can develop rapidly and mistakenly be attributed to other factors, particularly in a traumatic presentation. ${ }^{7}$ ECG changes have also been reported in association with a pneumopericardium. A literature review concluded associated ECG changes to be non-specific; these include ST segment changes, $\mathrm{T}$ wave inversion and decreased amplitude. ${ }^{8}$ These changes have been identified on presentation of a patient with pneumopericardium in one case report $^{9}$ and have been reported to develop shortly after presentation in another with extreme abnormalities developing over the following $12 \mathrm{~h} \cdot{ }^{10}$ An ECG is therefore indicated following the identification of a pneumopericardium on CT and telemetry may be indicated on patients with an initially normal ECG.

Pneumoperitoneum ${ }^{1}$ and retroperitoneum ${ }^{11}$ have been identified in other case reports in association with pneumomediastinum and surgical emphysema; this was not actively excluded in our patient by abdominal imaging due to the absence of any abdominal signs or symptoms. If present, peritoneal air would not alter the prospective management of this patient unless it became apparent and problematic clinically and hence inappropriate tests were avoided. 


\section{BMJ Case Reports}

\section{Learning points}

- Consider a pneumomediastinum as a cause for chest pain in patients with minor trauma and a normal respiratory examination.

- If a pneumomediastinum is identified on chest $x$-ray, $\mathrm{a}$ CT is advised to exclude tracking of the air into the pericardium and/or extradural space with potentially serious complications.

- Perform an abdominal examination and, if indicated, abdominal CT to exclude tracking of air into the peritoneum or retroperitoneum as has been identified in previous case reports.

- Most cases resolve spontaneously but there is the potential for life-threatening complications such a tension pneumopericardium.

- Patients with continued pneumopericardium and a normal initial ECG warrant a period of up to $12 \mathrm{~h}$ observation on telemetry.

Competing interests None.

Patient consent Obtained.

\section{REFERENCES}

1. Al-Mufarrej F, Gharagozloo F, Tempesta B, et al. Spontaneous cervicothoracolumbar pneumorrhachis, pneumomediastinum and pneumoperitoneum. Clin Respir J 2009;3:239-43.

2. Dyste KH, Newkirk KM. Pneumomediastinum in a high school football player: a case report. J Athl Train 1998;33:362-4.

3. Goh BK, Ng KK, Hoe MN. Traumatic epidural emphysema. Spine 2004;29:E528-30.

4. Levin S, Maldonado I, Rehm C, et al. Cardiac tamponade without pericardial effusion after blunt chest trauma. Am Heart J 1996;131:198-200.

5. Capizzi PJ, Martin M, Bannon MP. Tension pneumopericardium following blunt injury. J Trauma 1995;39:775-80.

6. Fulda G, Rodriguez A, Turney SZ, et al. Blunt traumatic pericardial rupture. A ten-year experience 1979 to 1989. J Cardiovasc Surg (Torino) 1990:31:525-30.

7. Petteruti F, Stassano P, De Luca G, et al. Tension pneumopericardium and pneumothorax during spontaneous ventilation. J Thorac Cardiovasc Surg 2007:133:829-30.

8. Brander L, Ramsay D, Dreier D, et al. Continuous left hemidiaphragm sign revisited: a case of spontaneous pneumopericardium and literature review. Heart 2002;88:5

9. Lucarelli K, Troisi F, Langialonga T. Pneumopericardium. Eur Heart J 2010;31:1953.

10. Konijn AJ, Egbers PH, Kuiper MA. Pneumopericardium should be considered with electrocardiogram changes after blunt chest trauma: a case report. J Med Case Reports 2008:2:100.

11. Shah SI, Applebaum EL. Spontaneous subcutaneous temporal emphysema. Am J Otolaryngol 2000;21:337-9.

This pdf has been created automatically from the final edited text and images.

Copyright 2011 BMJ Publishing Group. All rights reserved. For permission to reuse any of this content visit http://group.bmj.com/group/rights-licensing/permissions.

BMJ Case Report Fellows may re-use this article for personal use and teaching without any further permission.

Please cite this article as follows (you will need to access the article online to obtain the date of publication).

Minns T, Raj R, Clark K. A pain in the neck. BMJ Case Reports 2011;10.1136/bcr.09.2011.4840, date of publication

Become a Fellow of BMJ Case Reports today and you can:

- Submit as many cases as you like

- Enjoy fast sympathetic peer review and rapid publication of accepted articles

- Access all the published articles

- Re-use any of the published material for personal use and teaching without further permission

For information on Institutional Fellowships contact consortiasales@bmjgroup.com

Visit casereports.bmj.com for more articles like this and to become a Fellow 